\title{
A GESTÃo SUSTENTÁVEL COMO FERRAMENTA PARA O DESENVOLVIMENTO DAS SOCIEDADES
}

\section{ARTIGO ORIGINAL}

SILVA, Jacqueline da ${ }^{1}$

SILVA, Jacqueline da. A Gestão Sustentável como ferramenta para o desenvolvimento das sociedades. Revista Científica Multidisciplinar Núcleo do Conhecimento. Ano 05, Ed. 08, Vol. 01, pp. 25-33. Agosto de 2020. ISSN: 2448-0959, Link de acesso: https://www.nucleodoconhecimento.com.br/ciencias-sociais/gestaosustentavel

\section{RESUMO}

O presente artigo científico tem como tema Gestão Sustentável, seu objetivo é analisar os aspectos positivos e negativos da sustentabilidade ambiental na Gestão pública e conceitua-las. A gestão sustentável é norteada pela ideia de harmonizar aspectos sociais, ambientais e econômicos. A mesma deve se basear na preocupação com o ambiente, com o social e com sua situação financeira. Na Gestão Pública, por exemplo, a sustentabilidade se dá na medida em que todas as decisões tomadas pelo poder público devam priorizar a manutenção dos recursos e o melhor uso dos espaços, havendo uma preocupação com regras e fiscalizações que cumpram as metas sustentáveis. Este artigo tem a intenção de mostrar o que é sustentabilidade na Gestão pública. A metodologia utilizada se deu através de pesquisas em livros, textos e artigos científicos divulgados no meio eletrônico, onde foram coletados dados e informações sobre a temática em destaque. Dentre os autores pesquisados destaco: Galvão (2015), Lima (2007), Leff (2009), Peixoto (2013), dentre outros.

\footnotetext{
1 Pós-graduada em Gestão Pública e em Gestão de Pessoas na Administração Pública, graduada em Direito.
} 
Palavras-chave: Gestão, sustentabilidade, práticas ambientais.

\section{INTRODUÇÃO}

Uma gestão sustentável é norteada pela ideia de harmonizar aspectos sociais, ambientais e econômicos, tendo como foco a sustentabilidade de uma sociedade e a responsabilidade com os impactos das ações humanas para garantia não só do presente mais também do futuro.

Hoje em dia, com o crescimento rápido e contínuo da sociedade, a sustentabilidade tornou-se essencial para o bem estar da população e do mundo de uma forma geral. Neste contexto, pode-se dizer que a gestão sempre foi, e ainda será, uma condição indispensável para o desenvolvimento das sociedades.

Neste mesmo viés, a sustentabilidade se torna fator de suma importância para tornar o ambiente mais integrado, orgânico, preparado, protegido e dinâmico para lidar com as diversas demandas que surgem por conta da globalização e muitos outros fatores que influenciam na sustentabilidade.

Entender que Gestão Sustentável é algo fundamental, uma necessidade, torna o planejamento estratégico mais eficaz. Desse modo, ela é muito importante para se empreender numa visão e missão que forneçam respostas às demandas específicas da atualidade.

Levando em consideração a Gestão pública mediante os desafios enfrentados para administrar uma sociedade, este artigo tem como objetivo analisar os aspectos positivos e negativos da sustentabilidade ambiental na Gestão pública com a intenção de uma reflexão sobre a aproximação entre esses dois conceitos que devem estar integrados.

Assim, fundamenta-se o desenvolvimento deste artigo, pela preocupação com a ocorrência de danos ambientais, devendo ser investigados e penalizados, pois existe a necessidade da restauração imediata do meio ambiente e da implantação de 
Programas e Políticas Públicas que diminuam, ou até mesmo cessem essa degradação.

Pois, conforme expõe Grau (1992), a Constituição Federal protege a Ordem Econômica, sem contudo sacrificar o meio ambiente. Deste modo, foi necessário criar um mecanismo de desenvolvimento que equilibrasse os aspectos sociais, econômicos e ambientais, a fim de viabilizar a qualidade de vida das presentes e futuras gerações.

\section{DESENVOLVIMENTO}

A título de contextualizar, deve-se conceituar o que é Gestão pública e sustentabilidade para que esses conceitos deem margens à visão da sustentabilidade na Gestão.

Para Lima (2007), o termo "gestão pública" configura atos administrativos que visam corporificar, direta ou indiretamente, as políticas públicas. Portanto, ela contribui para o desenvolvimento urbano e econômico do município, mas devendo considerar todos os seus aspectos singulares, a fim de beneficiar todos os seus moradores.

Sustentabilidade é a habilidade das sociedades para satisfazer as necessidades do presente sem comprometer a possibilidade das futuras gerações de atenderem as suas necessidades (CMMAD, 1988).

Segundo Leff (2009) a sustentabilidade anuncia o limite da racionalidade econômica, proclamando os valores da vida, da justiça social e do compromisso com as gerações vindouras.

As junções dessas duas expressões representam muito, porém, muitas pessoas não sabem o seu significado e sua importância para uma vivência harmônica.

Cito Dowbor (2012, p.1080):

O ser humano vem de longa trajetória e tradição cultural de que a natureza é de certa maneira infinita, e o objetivo era dela conseguir extrair o máximo possível. A empresa que conseguisse tirar mais 
petróleo, derrubar mais matas, pescar mais peixe ou extrair mais água, tirando maior vantagem, mostrava os resultados como prova de sucesso, de competência.

Porém, essa questão mudou e, hoje, grande parte da população sofre com essas consequências.

Ainda segundo Dowbor (2007), em 1900 éramos 1,5 bilhão, atualmente passamos de 7 bilhões de pessoas, entretanto, o planeta não aumenta sua extensão geográfica. As tecnologias representam nossa maior esperança. Elas desempenham, se dúvida, um papel chave. Mas se o sinal é positivo ou negativo é uma grande pergunta (DOWBOR, 2007).

Com base nos pilares do desenvolvimento sustentável, é possível desenvolver ações nos âmbitos pessoal, comunitário e global, sendo eles capazes de minimizar os impactos negativos provocados pelo homem no meio em que vive.

$\mathrm{Na}$ tentativa de colocar em prática um desenvolvimento sustentado positivo os dirigentes públicos vêm tomando medidas que provocam mudanças nos valores vigentes da sociedade e também em seus próprios sistemas operacionais, como citamos acima, as tecnologias.

Os governos federal, estaduais e municipais vêm buscando se adequar às exigências de preservação com a ajuda de técnicas que utilizam racionalmente os recursos e evitam a poluição, por exemplo.

Às técnicas e/ou procedimentos foi dado o conceito de tecnologias limpas ${ }^{[2]}$, ou ambientalmente amigáveis. Estima-se que o uso de atividades e/ou instrumentos de tecnologias limpas permitirão aperfeiçoar sustentavelmente as técnicas e procedimentos necessários.

Vale lembrar que além das tecnologias limpas, existem ainda uma atividade de progresso para o Desenvolvimento Sustentado e a execução da atribuição de controle na qual a fiscalização das empresas privadas é a mesma do serviço público. 
Para Dettmer, Socorro, e Katon (2002), dentre as inúmeras ações e procedimentos que podem ser utilizados como tecnologias limpas gerenciais destacam-se:

- Melhoria da imagem e responsabilidade social - AS 8000;

- SIG - Informações geoespaciais para uso em cadastros multifinalitários, como mapeamento e monitoramento de parques, bancos genéticos, jazidas;

- Contabilidade e finanças ambientais públicas;

- Comunicações ecológicas - cartazes, cartilhas, mapas ecológicos, roteiros, campanhas;

- SGA - Sistema de Gestão Ambiental - ISO-14.000;

- Tributação como elemento restritivo à poluição;

- Auditoria ambiental;

- Projetos ecológicos de recuperação e melhoria ambiental;

- Plano de proteção ambiental à flora, fauna e recursos naturais;

- Agenda Marrom - qualidade sanitário-ambiental;

- Suprimentos de matérias-primas e insumos - não degradantes do meio;

- Parcerias e alianças estratégicas para viabilização de projetos ecológicos;

- Planejamento territorial urbano - Plano Diretor Ecológico;

- Zoneamento ecológico do município (DETTMER, SOCORRO, E KATON, 2002).

Segundo Freire (1994), a extensão territorial do Brasil dificulta sua fiscalização, e o desenvolvimento das técnicas exploratórias acelera o esgotamento dos seus recursos naturais.

Uma medida que poderá mudar esses aspectos é a educação ambiental, porque mesmo existindo as legislações específicas para a proteção do meio ambiente, notase que a sociedade aumentou suas atividades que degradam o ambiente em que vivemos.

Silva (2016) propõe que as mudanças de atitudes ocorram coletivamente, e a melhor forma de acontecer isso é através da educação. Faz-se necessário uma gestão em prol da educação ambiental. 
Peixoto (2013), em sua fala, diz que a sustentabilidade necessita de mudança de atitude dos indivíduos através de sua conscientização, que ocorre através das experiências cotidianas vividas por esses indivíduos, de modo que as práticas sustentáveis no ambiente educacional são necessárias para conscientizar e mudar os seus valores.

É preciso educar a população para isto, é preciso divulgar em diversos meios de comunicação que a preservação do meio ambiente é de suma importância para as gerações presentes e futuras.

Sendo assim, é necessário dizer que "a preservação dos recursos naturais e produtivos para as gerações futuras pode ser potencializada através da educação básica" (GAVIÃO; LIMA, 2015).

Segundo Pereira, Vilas Boas e Machado (2013), os indivíduos devem ter capacidade política, reflexiva e crítica a respeito do tripé da sustentabilidade ${ }^{[3]}$. Ao mesmo tempo, é necessário entender que a educação é o principal agente, incluindo a capacidade das pessoas de transformarem sua visão de mudança para o desenvolvimento sustentável.

Para Oliveira (2011), a conscientização das pessoas para a manutenção do meio ambiente equilibrado é de extrema relevância, bem como o desenvolvimento das ações governamentais, pois cooperam para a disseminação das responsabilidades sociais.

Para Barral e Ferreira (2006), todos os entes da federação devem colaborar para disponibilizar a todos um meio ambiente ecologicamente equilibrado, e portanto, são constitucionalmente responsáveis pela aplicação das políticas públicas que visam concretizá-lo.

A Comissão Mundial do Meio Ambiente e Desenvolvimento, relaciona desenvolvimento sustentável ao processo de crescimento das localidades, cujo principal objetivo é a conservação os recursos naturais, através do seu uso racional, incorporados às atividades produtivas. Destacam-se: 
- Crescimento renovável;

- Mudança de qualidade do crescimento;

- Satisfação das necessidades essenciais por emprego, água, energia, alimento e saneamento básico;

- Garantia de um nível sustentável da população;

- Conservação e proteção da base de recursos;

- Reorientação da tecnologia e do gerenciamento de risco;

- Reorientação das relações econômicas internacionais (CMMAD, 1988).

Como é possível observar através desta citação, a busca de alternativas sustentáveis se faz necessária para uma melhor qualidade de vida, seja ela urbana ou não. Exemplo:

Figura 01- Parâmetros de um desenvolvimento sustentável.

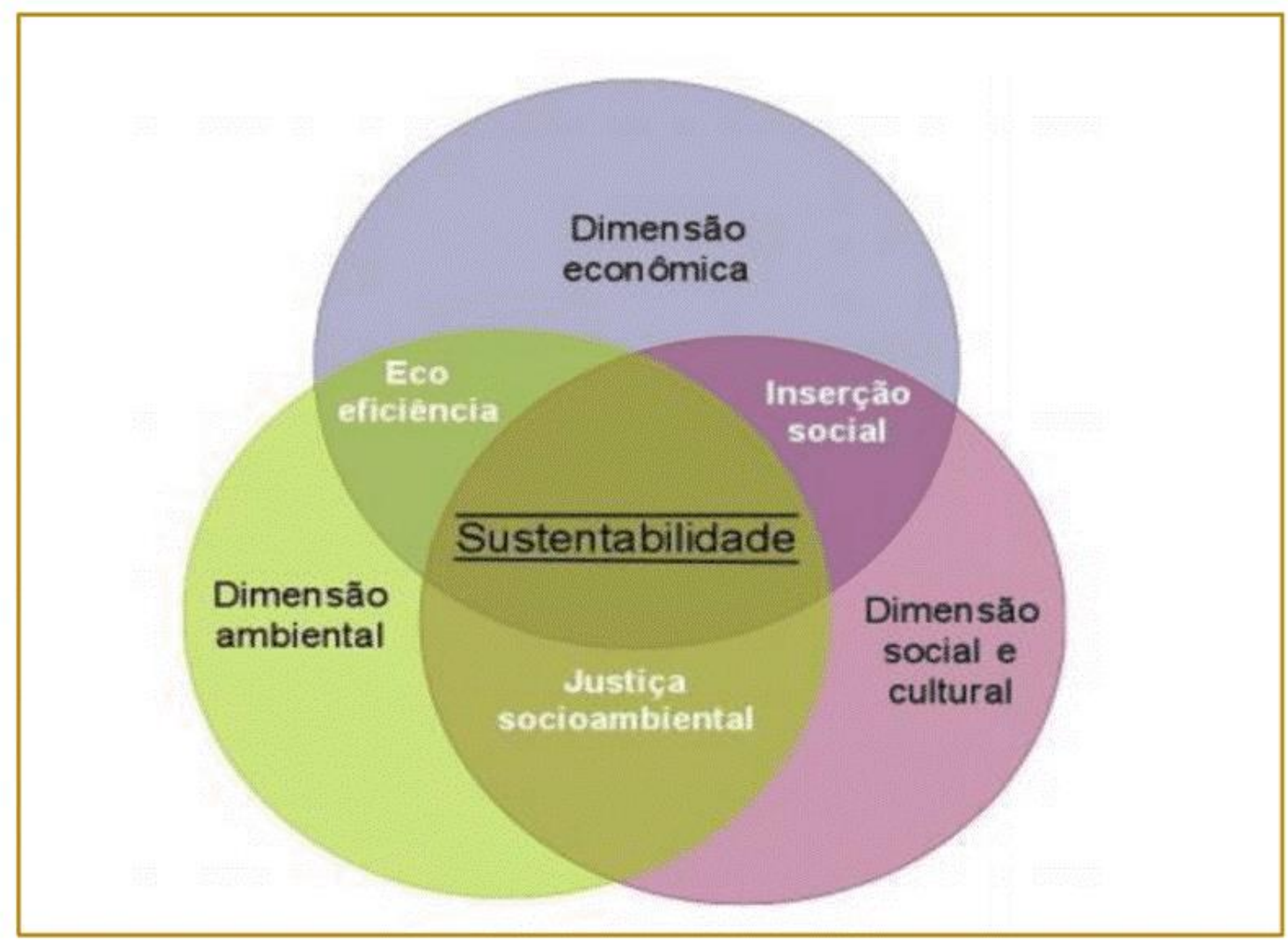

Fonte: Motta e Aguilar (2009 citado por BARROS; BARROS, 2015, pg. 12)

Fonte: Motta e Aguilar (2009). 
Portanto, é preciso ter uma integração de gestões para a realização de uma sustentabilidade com resultados, ou seja, uma Gestão Sustentável Integrada (GSI).

Para Tashizawa (2002), "[...] a gestão ambiental envolve a passagem do pensamento mecanicista para o sistêmico, no qual um aspecto essencial dessa mudança é que a percepção do mundo como máquina cede lugar à percepção como sistema vivo".

Ou seja, a gestão integrada busca essencialmente visões diferentes para as decisões de esferas e ações de sustentabilidade.

Desta maneira, pode-se dizer que a Gestão Pública Sustentável parte da ideia de que a administração pública deve ter como prioridade a transparência, o empenho e a competência na busca de resultados eficazes de forma operacional, tendo como objetivo a sustentabilidade.

A gestão sustentável é o termo utilizado por organizações que se preocupam com o meio ambiente. Expressa a conciliação de uma gestão que demonstre o lucro do negócio ou a economia de gastos com o controle dos efeitos da aquisição de materiais, contratação de serviços e desfazimento, que não sejam prejudicados por conta do lixo gerado ou dos gases expelidos (BARBIERI, 2006).

Hoje em dia é visível o grande desafio para a Administração Pública para desenvolver novos modelos de gestão, em que suas missões e objetivos estejam alinhados às responsabilidades em promover a preservação do meio ambiente (MUNCK; SOUZA, 2009).

Ou seja, a função principal da Gestão pública é a de prestar serviços e utilidades à coletividade, dentre esses serviços, a sustentabilidade, fator essencial para a sobrevivência humana. 


\section{CONCLUSÃO}

Através deste artigo, conclui-se que cada vez mais, faz-se necessário termos consciência e ações cuidadosas e respeitosas para com os recursos naturais, que cada vez mais tornam-se mais escassos.

É necessário que a população como um todo se adaptem e conscientizem a esta realidade "mundial", otimizando os recursos, preservando, reciclando e diminuindo a degradação ambiental na intenção de preservar o futuro hoje e das novas gerações.

A gestão sustentável é de grande importância para manter o equilíbrio ecológico. $\mathrm{Na}$ Gestão pública sustentável faz-se necessário manter o crescimento econômico de um determinado território para que se conservem os recursos naturais para que os mesmos sejam garantidos para as gerações futura.

É preciso ter esse equilíbrio. Para isto, é preciso ter uma gestão sustentável (ambiental) para conter a exploração dos recursos naturais e manter um nível econômico justo e igual a todos.

Pode-se dizer, a título de conclusão, que isto não é uma tarefa fácil. A promoção da sustentabilidade em grande parte do mundo tem sido um desafio, pois nem as pessoas estão dispostas a promover a conservação do meio ambiente.

Pois, não basta apenas uma gestão sustentável, é preciso a cooperação e a ajuda das pessoas como um todo. A Gestão Pública sustentável faz seu papel, porém parte da população não se empenha a isto, pois isso implicaria reduzir determinadas ações, como: produção industrial poluidora, desperdício e poluição de água.

Faz-se necessário que todos compreendam a ideia de que desenvolvimento sustentável não significa crescer menos economicamente, mas fazer a economia crescer com responsabilidade ambiental, lembrando sempre das futuras gerações.

Através dessa análise pode-se concluir também, que a gestão sustentável além de ser necessária deve ser praticada por todos. 


\section{REFERÊNCIAS}

BARBIERI, Jose Carlos. Gestão ambiental empresarial: conceitos, modelos e instrumentos. São Paulo: Editora Saraiva 2006.

BARRAL, W.; FERREIRA, G. A. Direito ambiental e desenvolvimento. In: BARRAL, W.; PIMENTEL, L. O. (Orgs.). Direito ambiental e desenvolvimento. Florianópolis: Fundação Boiteux, 2006.

CANEPA, Carla. Cidades Sustentáveis: o município como lócus da sustentabilidade. São Paulo: Editora RCS, 2007.

CMMAD - Comissão Mundial sobre Ambiente e Desenvolvimento. Nosso Futuro Comum. Rio de Janeiro. FGV, 1988.

DETTMER, Brígida; SOCORRO, Ceci; KATON, Heitor Takashi. Marketing de serviços - análise da percepção da qualidade de serviços através da ferramenta SERVQUAL em uma instituição de ensino superior de Santa Catarina. Revista de Ciências da Administração, Florianópolis, p. 60-74, jan. 2002. ISSN 2175-8077. Disponível em: <https://periodicos.ufsc.br/index.php/adm/article/view/1847>. Acesso em: 13/11/2019.

DOWBOR, Ladislau. Posfácio a gestão pública e sustentabilidade, ago. 2011. Disponível

em:

https://www.google.com.br/url?sa=t\&rct=j\&q=\&esrc=s\&source=web\&cd=1\&sqi=2\&ve d=0CDkQFjAA\&url=http\%3A\%2F\%2Fdowbor.org\%2Fblog\%2Fwpcontent\%2Fupload s\%2F2013\%2F01\%2F11Posf\%25C3\%25A1cio-Sampaio-aGest\%25C3\%25A3oP\%25C3\%25BAblica-

eSustentabilidade.doc\&ei=Ne5bUt_8J9ShqwGe5IC4Bw\&usg=AFQjCNHJVFuukDhR 22ObFyM8I-2gllPDWg\&bvm=bv.53899372,d.eW0. Acesso em: 14 de out, 2013.

FREIRE Ana MV. Imagens do meio ambiente: Fator GIS, n.7, ano 2, CuritibaPR: Sagres, 1994. 
GAVIÃO, L. O.; LIMA, G.B.A. Indicadores de sustentabilidade para a educação básica por modelagem fuzzy. REGET, Santa Maria, v. 19, n. 3, p. 274-297, set./dez. 2015.

GOES, G. A; MORALES, A. G. Gestão Pública e Sustentabilidade: Desafios, Ações e Possibilidades. Revista Fórum Ambiental da Alta Paulista, v. 9, n. 4, p. 199-212, 2013.

LEFF, E. Aventuras da epistemologia ambiental: da articulação das ciências ao diálogo dos saberes. Rio de Janeiro: Garamond Universitária, 2004. 87f. (Idéias Sustentáveis).

LIMA, Paulo Daniel Barreto. Excelência em Gestão Pública. Rio de Janeiro: Qualitymark, 2007.

MEADOWS, D. H.; MEADOWS, D. L.; RANDERS, L. Beyond the limits: confronting global collapse, envisioning a sustainable future. Vermont: Chelsea Green Publishing, 1992.

MUNCK, L.; SOUZA, R. B. A relevância do ser humano no contexto de institucionalização e legitimação do paradigma da sustentabilidade. Revista de gestão USP, São Paulo, v. 16, n. 3, p. 1-14, jul./set. 2009.

OLIVEIRA, M. C.; Informação e participação como instrumentos para a sustentabilidade. In: Mostra acadêmica UNIMEP, 9., 2011. Anais..., 2011.

PEIXOTO, M. F. C. C.; LIMA, J. R.; SANTOS, A. M. S.; CALEGARI, L. Percepção no Ambiente Acadêmico sobre Sustentabilidade Ambiental e o Uso do Papel. Caminhos de Geografia, Uberlândia, v. 14, n. 47, p. 74-84, 2013.

PEREIRA, A. S.; VILAS BOAS, A. A.; MACHADO, R. T. M. Educação Superior e sustentabilidade: um estudo sobre a percepção dos atores do Campus Alto Paraopeba/UFSJ/MG. Temas de Administração Pública, v. 8, n. 1, 2013. 
SILVA, S. G. Educação Ambiental Escolar: Estudando Teorias e Visualizando Iniciativas Realizadas no Colégio Módulo em Juazeiro do Norte-CE. Geosaberes, Fortaleza, v. 6, número especial 3, p. 16-26, Fev. 2016.

TACHIZAWA, Takeshy. Gestão ambiental e responsabilidade social corporativa: estratégias de negócios focadas na realidade brasileira. São Paulo: Atlas, 2002.

GRAU, Eros Roberto. Proteção do meio ambiente (Caso do Parque do Povo). Revista dos Tribunais, n. 702. São Paulo: Revista dos Tribunais, p. 251, 1992.

\section{APÊNDICE - REFERÊNCIAS DE NOTA DE RODAPÉ}

2. Tecnologias limpas são novos processos industriais ou alterações realizadas em processos já existentes, sempre com o objetivo de que o consumo de matériasprimas, o consumo energético, os impactos ambientais e o desperdício sejam sempre minimizados ou mesmo zerados.

3. O resultado de uma organização medido em termos sociais, ambientais e econômicos.

Enviado: Agosto, 2020.

Aprovado: Setembro, 2020. 